Gut, 1960, 1, 171.

\title{
SMOKING AND THE ALIMENTARY TRACT: A REVIEW
}

\author{
BY \\ R. S. PACKARD* \\ From the Department of Gastroenterology, Central Middlesex Hospital, London
}

\begin{abstract}
Because of inherent and inseparable variables, studies of the effect of smoking on gastric secretion and motility have proved inconclusive. The only firm conclusions to be drawn from the work reviewed are that the prognosis of both gastric and duodenal ulcers is made worse by regular smoking and that the healing and response of gastric ulcers to medical treatment is impaired. The mechanisms through which these effects are produced are unknown. It is not even certain that nicotine is the chief noxious agent in tobacco. Careful statistical and epidemiological studies have yielded such facts as exist and this approach seems the most promising one for future studies.
\end{abstract}

\section{Pharmacology of Tobacco}

Nicotine renders ganglion cells at first more sensitive and then more resistant to acetylcholine; there is therefore a transient stimulation followed by a more persistent depression of autonomic ganglia. The response to post-ganglionic stimulation is unimpaired. The effect of nicotine at any moment thus depends upon a summation of opposing effects. Salivary flow, for instance, may be stimulated then depressed. The subcutaneous injection of nicotine has been shown to cause nausea and vomiting, increased motor activity of the bowel, and perhaps diarrhoea with subsequent depression of intestinal tone and motility. This effect on the bowel can be blocked by atropine (Goodman and Gilman, 1955). It will be seen that the effects of smoking are less clear-cut than those of nicotine.

Nicotine is found in tobacco leaf as the salt of organic acids. Heat liberates the free base, which passes partly into the smoke where some is burned, but variable amounts enter the respiratory tract and are absorbed. The mean concentration of nicotine in cigarette tobacco is about $1.5 \%$ and the smoke from one cigarette may produce $6-8 \mathrm{mg}$. of nicotine. Of this, 3-4 mg. may be absorbed but the amount depends upon the moisture of the tobacco, the speed of smoking, the amount of inhalation, and the presence of a filter or cigarette holder. It is dependent also upon whether pipe, cigar, or cigarette is smoked (Goodman and Gilman, 1955; Batterman, 1955).

It is not clear how far the effects of smoking are due to nicotine, for tobacco contains other sub-

*This review was written while the author was the Royal Australasian College of Physicians' travelling scholar in medicine for 1959. stances which may be important: nornicotine, pyridine and other nitrogenous bases, volatile acids, tars, and phenols. These probably contribute to mucosal irritation but it is uncertain whether their concentration is high enough for systemic effects, although pyridine bases, for example, have been shown to cause nausea, vomiting, diarrhoea, and peripheral circulatory collapse (Dixon, 1927).

\section{EfFects of SMoking on the Stomach AND DUODENUM}

When these factors and the variety of impulses which influence gastric function are considered, it is hardly surprising that studies of the effects of smoking on gastric motility and secretion in health and disease have produced widely divergent findings. Wolf and Wolff (1943) found in their subject, Tom, that when he was out of sorts and smoking was unpleasant he became nauseated, stomach contractions ceased, the mucosa blanched, and secretions diminished. No such changes were observed when he was in good humour and found smoking pleasant. It has been pointed out, too, by Haag and Larson (1944) that the effect of smoking in a basal subject may bear little relation to its effect in a subject who is up and about. Such observations give some idea of the many variable factors involved.

GaSTRIC MotiLITY.-Inconstant changes in gastric motility are recorded after smoking. It has been observed in man and dog that whereas $1 \mathrm{mg}$. of nicotine subcutaneously has no effect, a few puffs of cigarette smoke may largely inhibit hunger contractions for an hour (Carlson, 1916; Schnedorf 
and Ivy, 1939). Perhaps this is the basis for the anorexia attributed to smoking but such inhibition has not been a constant finding in man. Batterman (1955), using intragastric balloons, showed three types of response in normal subjects and ulcer patients after smoking one cigarette. In one-third there was no effect, another third showed complete inhibition of motor activity for a time, and in the rest a period of hypermotility was followed by normal or subnormal activity. Batterman further observed that two cigarettes might sometimes cause an increase in motility and epigastric pain where one had no effect. Other workers have found that smoking has no significant effect on gastric emptying or motility (Schnedorf and Ivy, 1939; Dickson and Wilson, 1924; Steigmann, Dolehide, and Kaminski, 1954; Cooper, Harrower, Stein, and Moore, 1958).

Gastric SeCretion.-Smoking appears to produce more variable effects still on gastric secretion. Although some workers have found an increase in gastric secretion after smoking, most have observed no change. Some of the discrepancies can be explained by lack of a satisfactory and reproducible test of secretory function.

Schnedorf and Ivy (1939) investigated the effect of smoking on gastric secretion in non-smokers, smokers, and patients with duodenal ulcer. They found in all groups that just over one half showed an appreciable decrease in volume and acidity, a little over $40 \%$ showed no change, and in a few there was an increase in acidity in fasting specimens. In dogs with tracheotomies and Pavlov pouches they observed that two cigarettes caused slight depression in volume and acidity. In neither man nor dog was an effect on the secretory response to food observed. In a careful study in 147 male patients with duodenal ulcer, Cooper and Knight (1956) assessed the effect of smoking on volume, free acid, $p \mathrm{H}$, and concentration of pepsin. No significant difference was observed between the group which smoked and that which refrained. Others have made similar observations (Schliephake and Simmet, 1944; Hodges and Gilmour, 1950).

Other workers have found an increased acid output after smoking (Moll and Flint, 1928; Ehrenfeld and Sturtevant, 1941; Steigmann et al., 1954). Steigmann et al. (1954) observed the acid output after smoking in 44 normal subjects and 54 ulcer patients. They found that whereas in half the normal subjects the output of acid was increased after smoking, it was increased in over $90 \%$ of the ulcer patients. They concluded that ulcer patients show a greater acid response to smoking than normals. Piper and Raine (1959) attempted to eliminate one of the many variables by employing the augmented histamine test (Kay, 1953) as a measure of gastric secretion. They investigated 12 smokers, namely, three healthy students, three patients with peptic ulcer, and six patients with diseases not known to affect gastric function. All were fasting, none had smoked for 10 hours before the test, and in all the test was repeated. Basal secretion was estimated for one hour, each subject smoked four to six cigarettes during the second hour, and the augmented histamine test was performed in the third hour. On another occasion each subject was studied for two basal hours only so that each acted as his own control. Volume, total acid, and chloride content of gastric juice were found to be increased by smoking. The advantage of this over other studies lies in the fact that a reproducible test of gastric function was employed; other variables remained.

\section{EFFECT OF SMOKING ON DYSPEPSIA AND PePtic UlCer}

Many observers have commented that smoking aggravates dyspeptic symptoms (Gray, 1929a, b; Hurst and Stewart, 1929; Bockus, 1944; Schindler, 1947). Such observations have largely been uncontrolled and are dependent on subjective evidence. Jamieson, Illingworth, and Scott (1946) performed a more careful study. On questioning 473 ulcer patients they found that heavy cigarette smoking was associated with severe symptoms and pipe smoking with mild symptoms; a change in smoking habits did not influence the severity of symptoms. It was felt that this association was indirect and dependent on age, since severe symptoms and cigarette smoking tend to occur in the young while pipe smokers are older patients with milder symptoms. Batterman and Ehrenfeld (1949) found that smoking interferes with the medical management of peptic ulcer. In a group of 121 ulcer patients they found that smokers responded poorly to antacid therapy and had a higher incidence of acute exacerbations than nonsmokers. Partially "denicotinized" cigarettes improved the response to treatment and a return to standard tobacco caused a relapse.

More cogent evidence has been produced by Doll, Avery Jones, and Pygott (1958). In a careful study, which should be consulted in the original paper, they found for gastric and duodenal ulcers in both sexes more smokers among ulcer patients than among controls. The number of heavy smokers did not differ appreciably in each group and the proportion who smoked cigarettes only was higher among both gastric and duodenal ulcer subjects than among controls. They did not think smoking con- 
tributed directly to the production of ulcers because heavy smokers did not have a higher incidence of ulcer. They felt that either the presence of an ulcer might stimulate the desire to smoke or some psychological factor might predispose both to the development of an ulcer and to smoking. In a second study the same authors placed in-patient smokers with patients with gastric ulcers in two groups, one of which was advised to stop smoking. Otherwise management was the same. After four weeks the ulcers had healed significantly to a greater extent in the group advised to stop smoking. There was no difference in the amount of weight gain or in the severity of symptoms. It was concluded that in some patients smoking interferes with healing and helps to maintain chronicity. They thought that it was unlikely that tobacco was a direct cause of ulcer because tobacco consumption has increased in Great Britain in the past two or three decades whereas the incidence of gastric ulcer is thought to have diminished. In contrast, the incidence of duodenal ulcer has increased but its association with smoking is less. And the world distribution of mortality from peptic ulcer is quite unlike the distribution of smoking.

Hammond and Horn (1958) reported a follow-up of 187,783 men between the ages of 50 and 69 . Regular cigarette smokers had the highest mortality in all age groups. A high association was found between regular smoking and death from carcinoma of the lung, larynx, and oesophagus, and from gastric ulcer. The association was not so high with death from duodenal ulcer. Of 51 deaths from gastric ulcer, 48 occurred in regular smokers and none in non-smokers; there was no evidence that this was due to associated respiratory disease. Doll and Hill (1956) recorded similar findings. Edwards, McKeown, and Whitfield (1959), in reviewing the smoking habits of 1,737 men over 60 , found an increased incidence of peptic ulcer in smokers with a regular trend in prevalence according to the amount smoked.

Toon, Cross, and Wangensteen (1951) studied the effect of inhaling cigarette smoke in dogs with tracheotomies. Five cigarettes daily for six months produced no gastrointestinal lesion, but the same daily amount of smoke increased the ulcerogenic effect of daily injections of histamine in beeswax; the inhalation of more smoke in association with histamine gave a still higher incidence of ulcers while none were observed in control dogs. It was concluded that nicotine is the responsible agent because denicotinized smoke and histamine together cause few lesions. They also showed that in dogs cigarette smoke does not stimulate gastric secretion.

\section{OTHER EFFects OF TOBacco}

Salivary SeCretion.--Schnedorf and Ivy (1939) found that smoking increased salivary secretion in 15 chronic smokers and five non-smokers. This was probably a reflex change from mucosal irritation because $4 \mathrm{mg}$. of nicotine subcutaneously had no effect.

Carcinoma of Upper Alimentary Tract.A number of papers record an association between smoking and carcinoma of the lip (Levin, Goldstein, and Gerhardt, 1950), carcinoma of the buccal and pharyngeal regions (Mills and Porter, 1950), and carcinoma of the oesophagus (Hammond and Horn, 1958).

Pancreatic and Biliary Secretion.-Few reports on this subject are available. It seems that neither smoking nor nicotine influence pancreatic or biliary secretions (Schnedorf and Ivy, 1939; Koehler, Hill, and Marsh, 1947).

ThE CoLon.-Clinical observations suggest an association between smoking and colonic symptoms (Ryle, 1928; Bodley Scott, 1952). It has been shown in animals that nicotine applied on the floor of the fourth ventricle excites the activity of vomiting and defaecatory centres (Schnedorf and Ivy, 1939). These workers conducted a questionnaire addressed to 1,000 college students which revealed that $13 \cdot 7 \%$ of males and $17.3 \%$ of females passed a greater number of stools after excessive smoking. When small groups of students were submitted to smoking and non-smoking periods of three days each it was found that the predominant effect of smoking was to increase the motor activity of the colon (Schnedorf and Ivy, 1939). Grace, Wolf, and Wolff (1951) found no evidence of a change in colonic motility in habitual smokers after one cigarette.

MAlnutrition and Digestion.-There are surprisingly few reports in this connexion, despite the belief that smoking diminishes appetite and prevents weight gain. Koehler et al. (1947) observed the progress of six underweight patients who had reached their maximum weight on dietary measures. When they stopped smoking all gained between 7 and $14 \mathrm{lb}$. and the gain seemed to be due to improved appetite. Mitty, Rousselot, and Delany (1959) observed a large group of smokers and nonsmokers after gastrectomy for ulcer. They found no correlation between smoking and the amount of weight loss after operation; nor did smokers have more significant digestive complaints than nonsmokers. Smokers were, however, more liable to more major late complications such as recurrent ulcer. 


\section{REFERENCES}

Batterman, R. C. (1955). In The Biologic Effects of Tobacco, ed. E. L. Wynder, p. 133. Little, Brown, Boston

, and Ehrenfeld, I. (1949). Gastroenterology, 12, 575.

Bockus, H. L. (1944). Gastroenterology. Saunders, London.

Carlson, A. J. (1916). The Control of Hunger in Health and Disease. Úniversity of Chicago Press, Chicago.

Cooper, P., Harrower, H. W., Stein, H. L., and Moore, G. F. (1958) Gastroenterology, 35, 176 .

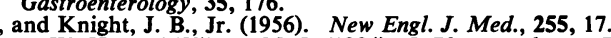

Dickson, W. H., and Wilson, M. J. (1924). J. Pharmacol. exp. Ther. $24,33$.

Dixon, W. E. (1927). Brit. med. J., 2, 719.

Doll, R., Avery Jones, F., and Pygott, F. (1958). Lancet, 1, 657.

-, and Hill, A. B. (1956). Brit. med. J., 2, 1071.

Edwards, F., McKeown, T., and Whitfield, A. G. W. (1959). Ibid., 1, 196.

Ehrenfeld, I., and Sturtevant, M. (1941). Amer. J. med. Sci., 201, 81

Goodman, L. S., and Gilman, A. (1955). The Pharmacological Basi. of Therapeutics, 2nd ed. Macmillan, New York.

Grace, W. J., Wolf, S., and Wolff, H. G. (1951). The Human Colon. Hoeber, New York.

Gray, I. (1929a). Amer. J. Surg., 7, 489.

(1929b). Ann. intern. Med, 3, 267.

Haag, H. B., and Larson, P. S. (1944). Virginia med. Monthly, 71, 235.

Hammond, E. C., and Horn, D. (1958). J. Amer. med. Ass., 166, 1159 and 1294.
Hodges, H. H., and Gilmour, M. T. (1950). N.C. med. J., 11, 249.

Hurst, A. F., and Stewart, M. J. (1929). Gastric and Duodenal Ulcer. Oxford University Press, London.

Jamieson, R. A., Illingworth, C. F. W., and Scott, L. D. W. (1946). Brit. med. J., 2, 287.

Kay, A. W. (1953). Ibid., 2, 77.

Koehler, A. E., Hill, E., and Marsh, N. (1947). Gastroenterology, $8,208$.

Levin, M. L., Goldstein, H., and Gerhardt, P. R. (1950). J. Amer.

Mills, C. A. Ass., 143, 336.

Mitty, W. F., Jr., Rousselot, L. M., and Delany, G. J. (1959). Ann. Surg., $150,76$.

Moll, H., and Flint, E. R. (1928). Brit. J. Surg., 16, 283.

Piper, D. W., and Raine, J. M. (1959). Lancet, 1, 696.

Ryle, J. A. (1928). Ibid. 2, 1115.

Schindler, R. (1947). Gastritis. Heinemann, London.

Schliephake, E., and Simmet, H. (1944). Dtsch. med. Wschr., 70, 363.

Schnedorf, J. G., and Ivy, A. C. (1939). J. Amer. med. Ass., 112, 898.

Scott, R. Bodley (1952). Brit. med. J., 1, 671.

Steigmann, F., Dolehide, R. H., and Kaminski, L. (1954). Amer. J. Gastroent., 22, 399.

Toon, R. W., Cross, F. S., and Wangensteen, O. H. (1951). Proc. Soc. exp. Biol. (N.Y.) 77, 866 .

Wolf, S., and Wolff, H. G. (1943). Human Gastric Function. Oxford University Press. New York. 